\title{
Solitary neurofibroma of eyelid masquerading as chalazion
}

This article was published in the following Dove Press journal:

International Medical Case Reports Journal

23 May 2017

Number of times this article has been viewed

\author{
Nancy Chen' \\ Yung-Hsiang $\mathrm{Hsu}^{2}$ \\ Yuan-Chieh Lee ${ }^{1,3}$ \\ 'Department of Ophthalmology, \\ Buddhist Tzu Chi General Hospital, \\ Hualien, Taiwan; ${ }^{2}$ Department \\ of Pathology, Buddhist Tzu Chi \\ General Hospital, Hualien, Taiwan; \\ ${ }^{3}$ Department of Ophthalmology and \\ Visual Science, Tzu Chi University, \\ Hualien, Taiwan
}

\begin{abstract}
Neurofibroma, a benign peripheral nerve sheath tumor, usually appears together with café-au-lait spots, iris nodules, and other tumors within the scope of neurofibromatosis von Recklinghausen type 1 tumors. A solitary neurofibroma of the eyelid is relatively rare. In this case report, we present a 39-year-old woman who had a lesion on the eyelid crease, previously treated as a chalazion. Due to persistent wound crusting, the lesion was excised above the tarsus. Pathological examination revealed a solitary neurofibroma. The patient did not have other clinical symptoms of neurofibromatosis, and there was no recurrence of the nodule during the 1-year follow-up.
\end{abstract}

Keywords: neurofibroma, eyelid tumor, chalazion

\section{Introduction}

Although eyelid lesions are mostly benign, ${ }^{1}$ obtaining an accurate clinical diagnosis remains challenging for primary physicians, dermatologists, and ophthalmologists in many circumstances. Various eyelid tumors of different origins can be masqueraded as chalazions, including sebaceous gland carcinomas, ${ }^{2}$ neurilemomas, ${ }^{3}$ and Merkel cell tumors, ${ }^{4}$ but seldom neurofibromas. ${ }^{5}$ Here, we report a neurofibroma of the eyelid simulating a persistent chalazion without a concurrent pathology of neurofibromatosis. This is a case report collected by clinical observation, surgical intervention, and pathological studies. Consent for publication was obtained from the patient.

\section{Case report}

A 39-year-old Taiwanese female had a painless eyelid mass on her right eye for 5 years. She had undergone blepharoplasty for trichiasis in her early 20 s, and there was no other remarkable past medical history such as trauma or systemic disease. She was treated by an incision and curettage for the eyelid mass 2 years prior at a local clinic after a tentative diagnosis of chalazion. No pathological examination of the curetted specimen was done at that time. However, the lesion did not subside after the procedure. Upon ophthalmic examination, a nodule with a crusted wound was found at the margin of the right upper eyelid (Figure 1). There were no other anomalies found in the fornix, anterior chamber or fundus. There was no palpable mass at the orbit and no restriction of eye movement.

The skin was incised horizontally at the wound, where necrotic tissue and soft tissue above the tarsus was excised for clinical pathology. The wound healed with no complications.
Correspondence: Yuan-Chieh Lee Department of Ophthalmology, Hualien Tzu Chi Hospital, 707 Sec 3, Chung Yung Road, Hualien 970, Taiwan Tel +88638561825 Ext 12169 Email yuanchieh.lee@gmail.com 


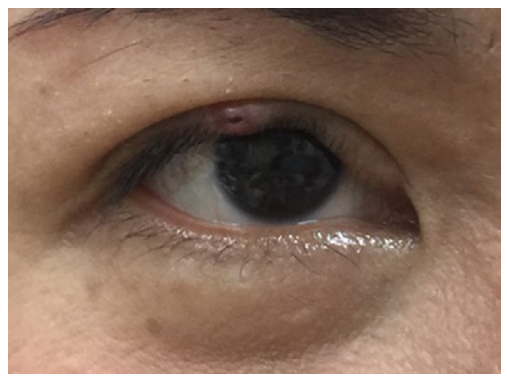

Figure I An elastic nodule with a crusted, poor-healing wound at the eyelid margin of the right eye.

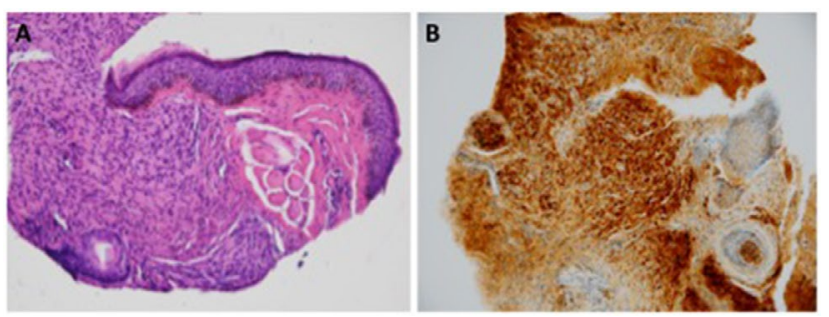

Figure 2 The histopathologic and histochemical studies of the solitary neurofibroma. Notes: (A) A well-circumscribed but unencapsulated collection of spindle cells within the eyelid dermis. Small bland wavy nuclei and small vascular channels are set within a myxoid background (H\&E stain, $\times 100)$. (B) Diffuse immune-reactive areas were revealed when stained with additional immunohistochemistry staining $\mathrm{SIOO}$, which indicates the presence of neural cells $(\times 100)$.

The histopathology results (Figure 2) showed a wellcircumscribed but unencapsulated collection of wavy-like spindle cells within a myxoid background. Immunohistochemistry stain showed a diffuse and strong S100 positive, indicating the presence of neural cells. These findings are diagnostic for neurofibroma.

Biomicroscopic examination did not reveal any Lisch nodules on the iris; meanwhile, neither light brown spots on the skin nor subcutaneous neurofibroma lesions were found elsewhere on the body. Therefore, her eyelid lesion was characterized as a localized neurofibroma. During the 1-year follow-up period, no recurrence of the tumor was noted on the eyelid.

\section{Discussion}

Neurofibromatosis Type 1 (NF1) is an autosomal dominant inherited disease with high penetrance. The NF1 gene is cloned on chromosome 17q11.2. ${ }^{6}$ The gene product, neurofibromin, is highly expressed in the nervous system and is regarded as a tumor suppressor. ${ }^{7}$ Commonly derived from neural crest mesenchyme, pathogenesis includes melanocytic lesions involving the skin and the eye, and neurogenic lesions (mostly glial cell lesions) such as nodular neurofibroma, plexiform neurofibroma, and optic glioma. According to the National Institutes of Health Consensus Development
Conference, the criteria for the diagnosis of NF1 include cafe-au-lait spots on the skin, neurofibroma, plexiform neurofibroma, freckles in the axilla or groin area, iris Lisch nodules, optic pathway glioma, bony dysplasia, and a firstdegree relative with NF1. However, the presentations are variable and even the individual carrying the gene has an unpredictable expression. ${ }^{8}$

Among the peripheral nerve sheath tumors involving the eye and adnexa, neurofibroma is the most common, followed by schwannoma tumors and neuromas. ${ }^{9}$ Whereas plexiform neurofibroma ${ }^{10}$ and multifocal neurofibroma are mostly associated with NF1, ${ }^{11}$ solitary neurofibroma of the eyelid can also present without other systemic involvement. ${ }^{12,13}$ Other locations for solitary neurofibroma include the tongue, ${ }^{14}$ palatine tonsil,${ }^{15}$ mandible,${ }^{16}$ and peritoneum. ${ }^{17}$

The eyelid skin, despite being thin, is composed of multiple histological elements and hence capable of harboring tumors of different origins. ${ }^{18}$ Huang et al ${ }^{1}$ reviewed 4,521 pathological specimens of eyelid tumors in a tertiary medical center and found $5 \%$ of them were malignant. Among those malignant tumors, basal cell carcinoma was most common (21.1\%), with squamous cell carcinomas coming in second (10.1\%).

Chalazion, the chronic lipogranulomatous inflammation of the sebaceous gland, is a relatively benign entity which is commonly encountered. However, a persistent lesion with a poorly healed wound should raise the suspicion of other etiologies. Several types of tumors, both benign and malignant, have been tentatively diagnosed as a chalazion and later proven otherwise. Ozdal et al ${ }^{19}$ retrospectively evaluated 1,060 cases with a clinical diagnosis of chalazion and found that, although mostly accurate, $6.4 \%$ cases were misdiagnosed. Among those, 15 cases (1.5\%) were malignant tumors. The most common malignant eyelid tumors on the misdiagnosed list were basal cell carcinomas, followed by sebaceous gland carcinomas.

\section{Conclusion}

Herein, we reported a case of a solitary eyelid neurofibroma without neurofibromatosis. The lesion on the eyelid margin appeared in the $4^{\text {th }}$ decade of the patient's life, previously masquerading as a chalazion. After the en bloc excision, our patient had no clinical evidence of nodule recurrence during the 1-year follow-up. In the current report, the solitary neurofibroma was on the eyelid margin and resembled granulation tissue of chronic inflammation, differing from one beneath the tarsal plate in the previous article by Shibata et al. ${ }^{5}$ Although the presentation of this benign entity varied from that of a traditional neurofibroma, it should be included as a differential diagnosis with eyelid lesions. We would also 
like to emphasize that a histopathological evaluation is recommended for persistent or atypical chalazions of the eyelid.

\section{Disclosure}

The authors report no conflicts of interest in this work.

\section{References}

1. Huang YY, Liang WY, Tsai CC, Kao SC, Yu WK, Kau HC, Liu CJ Comparison of the clinical characteristics and outcome of benign and malignant eyelid tumors: an analysis of 4521 eyelid tumors in a tertiary medical center. Biomed Res Int. 2015;2015:453091.

2. Gerber DM, Meyer P, Messerli JO, Piffaretti JM, Haefliger IO. Maskerade eines Talgdrüsenkarzinoms durch ein rasch rezidivierendes "Chalazion", eine Kasuistik. [Masquerade of sebaceous gland carcinoma as a rapidly recurring "chalazion", a case report]. Klin Monbl Augenheilkd. 2001;218(5):391-393. German.

3. Shields JA, Guibor P. Neurilemoma of the eyelid resembling a recurrent chalazion. Arch Ophthalmol. 1984;102(11):1650.

4. Rawlings NG, Brownstein S, Jordan DR. Merkel cell carcinoma masquerading as a chalazion. Can J Ophthalmol. 2007;42(3):469-470.

5. Shibata N, Kitagawa K, Noda M, Sasaki H. Solitary neurofibroma without neurofibromatosis in the superior tarsal plate simulating a chalazion. Graefes Arch Clin Exp Ophthalmol. 2012;250(2):309-310.

6. Viskochil D, Buchberg AM, Xu G, et al. Deletions and a translocation interrupt a cloned gene at the neurofibromatosis type 1 locus. Cell. 1990;62(1):187-192.

7. Daston MM, Scrable H, Nordlund M, Sturbaum AK, Nissen LM, Ratner $\mathrm{N}$. The protein product of the neurofibromatosis type 1 gene is expressed at highest abundance in neurons, Schwann cells, and oligodendrocytes. Neuron. 1992;8(3):415-428.
8. Ferner RE, Huson SM, Thomas N, et al. Guidelines for the diagnosis and management of individuals with neurofibromatosis 1. JMed Genet. 2007;44(2):81-88

9. Zhang ML, Suarez MJ, Bosley TM, Rodriguez FJ. Clinicopathologic features of peripheral nerve sheath tumors involving the eye and ocular adnexa. Hum Pathol. Epub 2017 Feb 21.

10. Chaudhry IA, Morales J, Shamsi FA, et al. Orbitofacial neurofibromatosis: clinical characteristics and treatment outcome. Eye (Lond). 2012;26(4):583-592.

11. Jain G, Jain VK, Sharma IK, Sharma R, Saraswat N. Neurofibromatosis type 1 presenting with ophthalmic features: a case series. J Clin Diagn Res. 2016;10(11):SR01-SR03.

12. Shields JA, Shields CL. Atlas of eyelid and conjunctival tumors. Philadelphia, PA: Lippincott Williams \& Wilkins; 1999;96-97.

13. Stagner AM, Jakobiec FA. Peripheral nerve sheath tumors of the eyelid dermis: a clinicopathologic and immunohistochemical analysis. Ophthal Plast Reconstr Surg. 2016;32(1):40-45.

14. Mahmud SA, Shah N, Chattaraj M, Gayen S. Solitary encapsulated neurofibroma not associated with neurofibromatosis- 1 affecting tongue in a 73-year-old female. Case Rep Dent. 2016;2016:3630153.

15. Madhumita K, Nambiar A, Prathapan P. Solitary neurofibroma of the palatine tonsil: a case report. Ear Nose Throat J. 2007;86(12): 756-758.

16. Narang BR, Palaskar SJ, Bartake AR, Pawar RB, Rongte S. Intraosseous neurofibroma of the mandible: a case report and review of literature. J Clin Diagn Res. 2017;11(2):ZD06-ZD08.

17. Barajas-Gamboa JS, Florez-Salamanca L. Solitary neurofibroma in the abdominal wall of a patient without neurofibromatosis: case report. Biomedica. 2009;29(4):501-505.

18. Pe'er J. Pathology of eyelid tumors. Indian J Ophthalmol. 2016;64(3): 177-190.

19. Ozdal PC, Codere F, Callejo S, Caissie AL, Burnier MN. Accuracy of the clinical diagnosis of chalazion. Eye (Lond). 2004;18(2):135-138.
International Medical Case Reports Journal

\section{Publish your work in this journal}

The International Medical Case Reports Journal is an international, peer-reviewed open-access journal publishing original case reports from all medical specialties. Previously unpublished medical posters are also accepted relating to any area of clinical or preclinical science. Submissions should not normally exceed 2,000 words or

\section{Dovepress}

4 published pages including figures, diagrams and references. The manuscript management system is completely online and includes a very quick and fair peer-review system, which is all easy to use. Visit http://www.dovepress.com/testimonials.php to read real quotes from published authors. 